\title{
Differential glomerular immunoexpression of matrix metalloproteinases MMP-2 and MMP-9 in idiopathic IgA nephropathy and Schoenlein-Henoch nephritis
}

\author{
Marian Danilewicz, Małgorzata Wągrowska-Danilewicz
}

\author{
Department of Nephropathology (Morphometry Division), Medical University of Łódź.
}

\begin{abstract}
Both idiopathic IgA nephropathy (IgAN) and Schoenlein-Henoch nephritis (SHN) are characterized by cell proliferation and abnormal extracellular matrix (ECM) remodeling by mesangial cells leading to fibrosis, sclerosis and endstage renal disease. Matrix metalloproteinases MMP-2 and MMP-9 are reported as the most important proteolytic enzymes involved in remodeling of ECM. Therefore, the aim of the present study was to determine glomerular immunoexpression of MMP-2 and MMP-9 in IgAN and SHN. Another purpose of this study was to examine the relationship between expression of MMPs and mesangial cells, a-smooth muscle actin $(\alpha-S M A)$ staining, and monocytes/macrophages. Fifteen patients with idiopathic IgAN and 12 with SHN were examined by percutaneous renal biopsy. Glomerular staining intensity of MMP-2 and MMP-9 was recorded semiquantitatively, whereas mesangial cells, glomerular $\alpha$-SMA staining and glomerular CD 68+ cells were assessed quantitatively using computer image analysis system. Our study revealed that the mean values of glomerular immunoexpression of MMP-2, mesangial cells, $\alpha$-SMA staining and glomerular CD 68+ cells were in SHN patients significantly increased as compared to IgAN cases whereas glomerular staining for MMP-9 did not differ in these groups. Moreover, a glomerular staining of MMP-2 was significantly positively correlated with mesangial cells as well as glomerular $\alpha$-SMA staining in both SHN and IgAN. A positive significant correlation between glomerular MMP-2 staining and glomerular CD68+ cells was noted only in SHN group. The correlations of glomerular MMP-9 and these parameters were weak and not significant. In conclusion, our results confirm increased glomerular staining of MMP-2 but not MMP-9 in SHN patients. A suggestion that augmented mesangial cells proliferation in these cases depends on MMP-2, $\alpha$-SMA and monocytes/macrophages needs further investigations including double staining study.
\end{abstract}

Key words: MMP-2, MMP-9, glomerulonephritis

\section{Introduction}

In 1985 Meadow and Scott proposed that Berger's disease could be regarded as Schoenlein-Henoch purpura without the rash [1]. This assumption is supported by several features. Glomerular and dermal deposition of $\operatorname{IgA}$ is found in both diseases, and the same types of glomerular lesions are seen by light microscopy, electron microscopy and by immunofluorescence [2]. Moreover, patients with nephritis associated with Schoenlein-Henoch purpura who undergo renal transplantation have recurrence of IgA deposits in the graft in the absence of extrarenal symptoms, as do patients with Berger's disease [3]. On the other hand, the

Correspondence: M. Danilewicz, Dept. of Nephropathology

(Morphometry Division), Medical University of Łódź,

Pomorska Str. 251, 92-216 Łódź, Poland;

tel./fax.: (+4842) 6757633, e-mail: hobo@csk.umed.lodz.pl epithelial crescents and glomerular proliferative changes in patients with SHN were reported to be more severe than in IgAN $[2,4]$, and the molecular weight of the immune complexes has been found to be higher in SHN than in Berger's disease [5]. Moreover, in childhood, the prognosis of SHN seems to be worse than that of IgAN [6]. Both IgAN and HSN display alterations in the proliferation of glomerular cells and the content or composition of the extracellular matrix [ECM] compartment leading to fibrosis, sclerosis and end-stage renal disease [7].

In the last decade matrix metalloproteinases (MMPs) are reported as the most important proteolytic enzymes involved in remodeling of ECM, and are crucial for tissue development and homeostasis. MMPs are classified into six groups based on substrate and sequence homology. Gelatinases: MMP-2 (gelatinase A) and MMP-9 (gelatinase B) cleave the denatured collagens (gelatins) and laminin, as well as some 
Table 1. Clinical findings at the time of biopsy in cases with IgAN and SHN.

\begin{tabular}{|c|c|c|c|c|c|c|c|c|}
\hline Group & \multirow{2}{*}{$\begin{array}{c}\text { Sex } \\
\text { M:l' }\end{array}$} & $\begin{array}{c}\text { Micro } \\
\text { hematuria }\end{array}$ & $\begin{array}{c}\text { Gross } \\
\text { hematuria }\end{array}$ & \multicolumn{3}{|c|}{ Proteinuria } & Renal function & Hypertension \\
\cline { 5 - 7 } & & $<1 \mathrm{~g} / 24 \mathrm{~h}$ & $1-2 \mathrm{~g} / 24 \mathrm{~h}$ & $2-3 \mathrm{~g} / 24 \mathrm{~h}$ & & \\
\hline $\begin{array}{c}\text { IgAN } \\
(\mathrm{n}=15)\end{array}$ & $5: 10$ & 14 & 1 & 8 & 4 & - & 2 & 2 \\
\hline $\begin{array}{c}\text { SHN } \\
(\mathrm{n}=12)\end{array}$ & $8: 4$ & 5 & 7 & 4 & - & 1 & - & 2 \\
\hline
\end{tabular}

Values in the table are number of cases. ${ }^{1}$ Serum creatinine $>1.5 \mathrm{mg} / \mathrm{dl}$

chemokines [8]. MMP-2 can also activate MMP-1 and MMP-9 by cleaving their prodomains [9]. Recent study also demonstrated that gelatinases are involved in the process of epithelial to mesenchymal transformation (EMT) in renal tissue [10,11]. The hallmarks of activation of mesangial as well as tubular cells are de novo expression of $\alpha$-smooth muscle actin ( $\alpha$-SMA) and overproduction of the interstitial matrix components [12]. Additionally, it was suggested that during inflammation monocytes/macrofages may produce MMP-2 and MMP-9 [6].

Therefore, the aim of the present study was to determine glomerular immunoexpression of MMP-2 and MMP-9 in IgAN and SHN. Another purpose of this study was to examine the relationship between immunoexpression of MMPs and mesangial cells, $\alpha$-SMA staining and monocytes/macrophages.

\section{Materials and methods}

Patients. Fifteen patients with idiopathic IgAN (mean age $25.4 \pm 9.4$ ) and 12 with SHN (mean age 19.6 \pm 8.6 ) were examined by percutaneous renal biopsy. For the present study only cases with diffuse mesangial proliferation were selected. In all cases, diagnosis of IgAN and SHN was based on characteristic findings by light microscopy (sections stained with hematoxylin and eosin, MassonTrichrome, Jones' silver impregnation and periodic acid-Schiff followed by Alcian Blue) as well as immunofluorescence and electron-microscopy using standard protocols. Thickness of each section was controlled according to the method described by Weibel [13]. In each case of SHN diagnosis was confirmed clinically. Clinical features of the patients at the time of biopsy are given in Table 1. Most of our patients were children and young adults. Male predominance was noticeable in both IgAN and SHN groups. At the time of renal biopsy all patients with IgAN and SHN showed hematuria. Proteinuria accompanied hematuria in $3 \operatorname{IgAN}$ and 5 SHN cases. Clinical renal impairment (serum creatinine greater than $1.5 \mathrm{mg} / \mathrm{dl}$ ) was noted only in 2 IgAN patients. Elevated blood pressure had $2 \mathrm{IgAN}$ and $2 \mathrm{SHN}$ patients.

Immunohistochemistry. Paraffin sections were mounted onto superfrost slides, deparaffinized, then treated in a microwave oven in a solution of citrate buffer, $\mathrm{pH} 6.0$ for $20 \mathrm{~min}$ and transferred to distilled water. Endogenous peroxidase activity was blocked by $3 \%$ hydrogen peroxide in distilled water for $5 \mathrm{~min}$, and then sections were rinsed with Tris-buffered saline (TBS, DakoCytomation, Denmark) and incubated with: monoclonal mouse-antihuman matrix metalloproteinase-2 (clone 17B11, Novocastra Lab., dilution 1:50), monoclonal mouse anti-human matrix metalloproteinase -9 (clone 15W2, Novocastra Lab., dilution 1:100), $\alpha$-SMA (clone P1b5, DakoCytomation, Denmark, dilution 1:50), and mon- oclonal mouse anti-human CD68 antibody (DakoCytomation, Denmark, dilution 1:100). Afterwards LSAB+/HRP Universal kit (DakoCytomation, Denmark) prepared according to the instructions of the manufacturer was used. Visualisation was performed by incu-

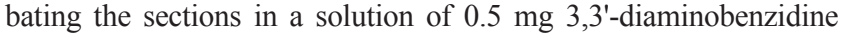
(DakoCytomation, Denmark), per ml Tris-HCl buffer, $\mathrm{pH}$ 7.6, containing $0.02 \%$ hydrogen peroxide, for $10 \mathrm{~min}$. After washing, the sections were counter-stained with hematoxylin and coverslipped. For each antibody and for each sample a negative control were processed. Negative controls were carried out by incubation in the absence of the primary antibody and always yielded negative results.

In each specimen staining intensity of MMP-2 and MMP-9 was recorded in all glomeruli semiquantitatively by two independent observers and graded from 0 (staining not detectable), 1 (weak diffuse staining with only focally increased mesangial staining), 2 (mild staining with focally strong mesangial staining) and 3 (strong staining of the glomerular tuft). The mean grade was calculated by averaging grades assigned by the two authors and approximating the arithmetical mean to the nearest unity.

Morphometry. Histological morphometry was performed by means of image analysis system consisting of a PC computer equipped with a Pentagram graphical tablet, Indeo Fast card (frame grabber, true-color, real-time), produced by Indeo (Taiwan), and color TV camera Panasonic (Japan) coupled to a Carl Zeiss microscope (Germany). This system was programmed (MultiScan 8.08 software, produced by Computer Scanning Systems, Poland) to calculate the number of objects (semiautomatic function) and the surface area of a structure using stereological net (with regulated number of points). The coloured microscopic images were saved serially in the memory of a computer, and then quantitative examinations had been carried out.

Alpha-SMA staining per cent of total glomerular area was measured using point counting method which is an adaptation of the principles of Weibel [13]. The point spacing being $16 \mu \mathrm{m}$. Total numbers of the points of a net was 169 , and total area was 36864 sq. $\mu \mathrm{m}$. The percentage of $\alpha$-SMA staining was an expression of the number of points overlying these structures as a percentage of the total points counted.

Glomerular monocytes/macrophages were determined by counting CD68+ cells (semiautomatic function). Only immunoreactive cells with the clear identifiable nucleus were counted. Cells were scored positive when displayed a distinctly brown membrane. Extracapillary cells, such as in crescents, where present, were excluded from the count of intraglomerular immune cells. The number of positive cells per glomerular cross-section in each section was obtained and used in the analysis. The same method was used to determine mesangial cells in sections stained with periodic acid-Schiff followed by Alcian Blue).

Statistical analysis. Differences between groups were tested using unpaired Student's t-test preceded by evaluation of normality and Levene's test. The Mann-Whitney U test was used where appropriate. Correlation coefficient was calculated using Spearman's method. Results were considered statistically significant if $\mathrm{p}<0.05$. 

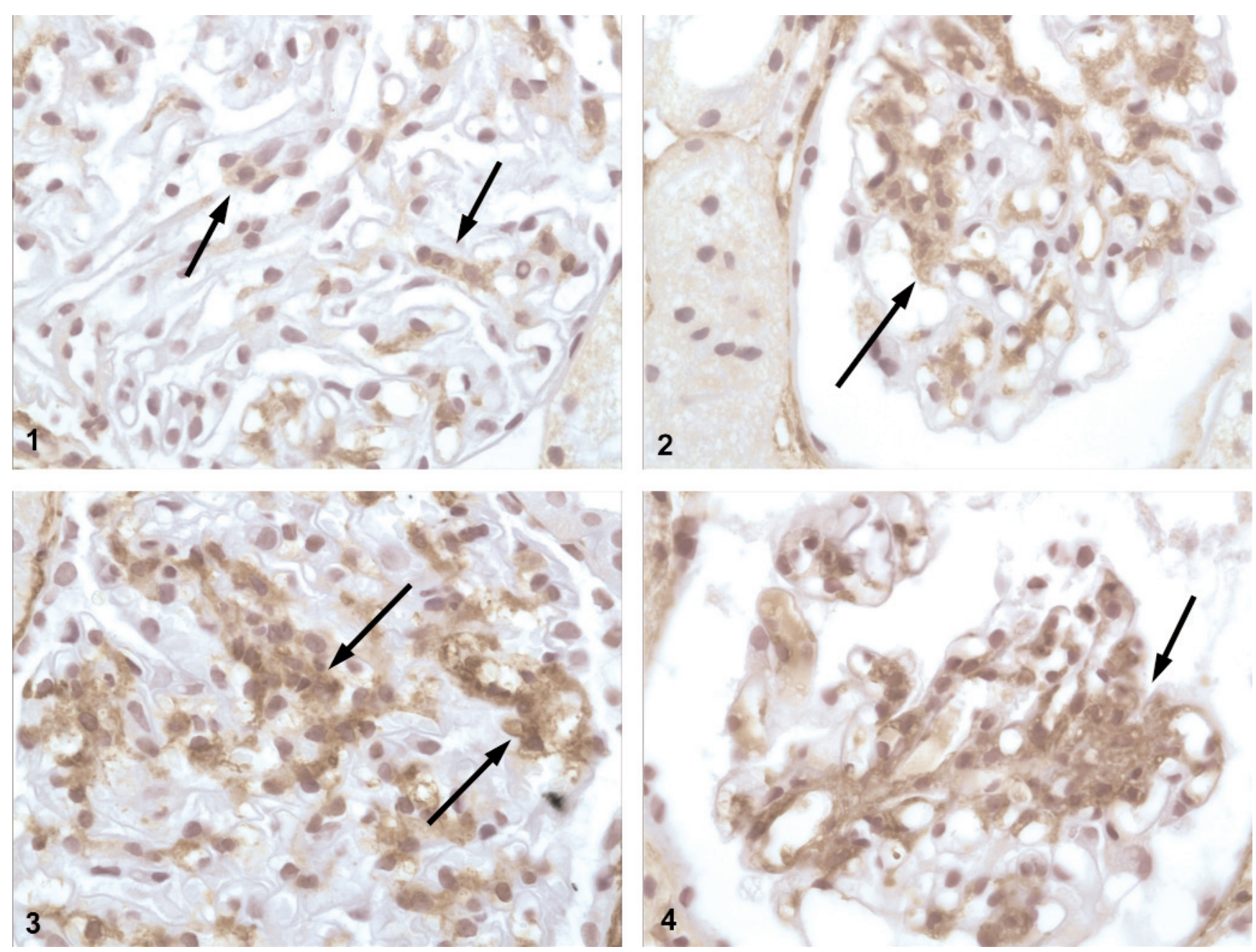

Fig. 1. Weak mesangial immunoexpression of MMP-2 in kidney biopsy in patient with IgAN. Immunostaining with antibody against MMP-2 (original magnification $\times 400$ ). Fig. 2. Moderate immunoexpression of MMP-2 in kidney biopsy in patient with SHN. Immunostaining with antibody against MMP-2 (original magnification $\times 400$ ). Fig. 3. Strong immunoexpression of MMP-9 in kidney biopsy in patient with IgAN. Immunostaining with antibody against MMP-9 (original magnification $\times 400$ ). Fig. 4. Similarly like in IgAN intense mesangial staining for MMP-9 can be seen in patient with SHN. Immunostaining with antibody against MMP-9 (original magnification $\times 400)$.

\section{Results}

In IgAN and SHN glomerular staining for both MMP2 and MMP-9 were found mainly in the mesangial regions and in some periglomerular cells (Fig. 1-4). Additionally weak staining was noted in the tubular epithelial cells and focally in the interstitium, but in the present study this extraglomerular immunoexpression of MMP-2 and MMP-9 was not taken into consideration.

A morphometric and semiquantitative comparison of glomerular parameters in cases with IgAN and SHN appear from Table 2. The mean values of glomerular immunoexpression of MMP-2, mesangial cells, $\alpha$-SMA staining and glomerular monocytes/ macrophages were in SHN patients significantly increased as compared to IgAN cases whereas glomerular staining for MMP-9 did not differ in these groups. Moreover, a glomerular immunoexpression of MMP-2 was significantly positively correlated with mesangial cells as well as glomerular $\alpha$-SMA staining in both SHN and IgAN (Table 3). On the other hand, a positive significant correlation between glomerular MMP-2 staining and glomerular monocytes/ macrofages was noted only in SHN group. The correlations of glomerular MMP-9 staining and these parameters were weak and not significant.

\section{Discussion}

Both IgAN and SHN are characterized by cell proliferation and abnormal ECM remodeling by mesangial cells [14]. Glomerular mesangial cells are embedded in the mesangial matrix and control its turnover through a dynamic equilibrium between synthesis and degradation [15]. The regulation of ECM remodeling in the 
Table 2. A morphometric and semiquantitative comparison of glomerular parameters in cases with IgAN and SHN. Data are expressed as mean $\pm \mathrm{SD}$

\begin{tabular}{|l|c|c|c|}
\hline & $\begin{array}{c}\text { IgAN } \\
(\mathrm{n}=15)\end{array}$ & $\begin{array}{c}\text { SIIN } \\
(\mathrm{n}=12)\end{array}$ & P value \\
\hline Glomerular immunoexpression of MMP-2 (semiquantitative score) & $0.4 \pm 0.2$ & $0.7 \pm 0.4$ & $<0.02$ \\
\hline Glomerular immunoexpression of MMP-9 (semiquantitative score) & $1.4 \pm 0.5$ & $1.8 \pm 0.6$ & $=0.07(\mathrm{NS})$ \\
\hline Mesangial cells per total glomerular area & $66.4 \pm 15.6$ & $86.3 \pm 18.9$ & $<0.007$ \\
\hline Glomerular $\alpha$-SMA staining (\% of total glomerular area) & $3.7 \pm 1.8$ & $5.6 \pm 2.4$ & $<0.03$ \\
\hline CD68+ cells/glomerular cross-section & $2.7 \pm 1.2$ & $4.2 \pm 2.2$ & $<0.04$ \\
\hline
\end{tabular}

Table 3. Spearman rank order correlations between glomerular immunoexpression of MMPs and mesangial cells, $\alpha$-SMA as well as monocytes/macrophages in patients with IgAN and SHN

\begin{tabular}{|l|c|c|}
\hline \multicolumn{1}{|c|}{ Pair of variables } & \multicolumn{1}{|c|}{$\begin{array}{c}\mathrm{Ig} \wedge \mathrm{N} \\
(\mathrm{n}=15)\end{array}$} & $\begin{array}{c}\mathrm{SHN} \\
(\mathrm{n}=12)\end{array}$ \\
\hline Glomerular immunoexpression of MMP-2 and mesangial cells & $\mathrm{r}=0.54, \mathrm{p}<0.04$ & $\mathrm{r}=0.62, \mathrm{p}<0.04$ \\
\hline Glomerular immunoexpression of MMP-2 and glomerular $\alpha$-SM $\wedge$ staining & $\mathrm{r}=0.62, \mathrm{p}<0.02$ & $\mathrm{r}=0.71, \mathrm{p}<0.01$ \\
\hline Glomerular immunoexpression of MMP-2 and glomerular and CD68+ cells & $\mathrm{r}=-0.49, \mathrm{p}=0.07$ (NS) & $\mathrm{r}=0.67, \mathrm{p}<0.02$ \\
\hline Glomerular immunoexpression of MMP-9 and mesangial cells & $\mathrm{r}=-0.49, \mathrm{p}=0.07$ (NS) & $\mathrm{r}=0.54, \mathrm{p}=0.07$ (NS) \\
\hline Glomerular immunoexpression of MMP-9 and glometular $\alpha-\mathrm{SM} \wedge$ staining & $\mathrm{r}=-0.39, \mathrm{p}=0.15$ (NS) & $\mathrm{r}=-0.53, \mathrm{p}=0.07$ (NS) \\
\hline Glomerular immunoexpression of MMP-9 and glomerular and CD68+ cells & $\mathrm{r}=0.32, \mathrm{p}=0.24$ (NS) & $\mathrm{r}=0.51, \mathrm{p}=0.09$ (NS) \\
\hline
\end{tabular}

kidney by MMPs has previously been studied by use of models of interstitial fibrosis and glomerular sclerosis $[16,17]$. However, there are only a few reports examining the role of MMPs in human glomerulonephritis [14] and glomerular immunolocalisation of MMP-2 and MMP-9 is still a matter of controversies. Sanders et al. [18] found in human ANCA-associated glomerulonephritis immunoexpression of MMP-2 in glomerular and periglomerular cells whereas in study of Urushihara et al.. [14] immunoreactvities to MMP-2 were not detected on glomerular tufts in controls or in patients with any types of glomerulonephritis. It is noteworthy that this latter study included also 20 patients with IgAN and 4 with SHN. In contrast to Urushihara et al. [14] we revealed immunoexpression of MMP-2 in the mesangial regions and in some periglomerular cells in all IgAN and SHN patients. On the other hand, similarly like these authors, we found strong glomerular immunoexpression of MMP-9 in both groups investigated. The glomerular immunolocalisation of MMP-9 was the same as MMP-2. Interestingly, Sanders et al. [18] found in ANCA-associated glomerulonephritis immunoexpression of MMP-9 only in glomeruli with active crescents.

Our study revealed significantly increased glomerular immunoexpression of MMP-2 but not MMP-9 in SHN group as compared with IgAN patients. These two gelatinases have ability to breakdown components of the basement membrane and col- lagens, and in vitro both enzymes have a very similar substrate profile [19]. Matrix-degrading enzymes are historically considered to reduce matrix accumulation, thereby attenuating renal fibrosis after injury. However, recent genetic studies using knock-out mice have painted a different and complex picture of the function of these proteins in relation to fibrotic lesions in vivo [10-12]. The biologic role of MMP-2 was first analyzed in cultured rat mesangial cells $[20,21]$. In these cells, the constitutive synthesis of MMP-2 was almost completely inhibited. The noticeable differences included changes in synthesis of ECM proteins, loss of the activation marker $\alpha$-SMA and almost total arrest of cell proliferation. The direct effect of MMP-2 on mesangial cell proliferation was latter confirmed in vivo, since infusion of activated MMP-2 into renal artery demonstrated focal areas of mesangial cell proliferation in rat glomeruli $[21,22]$. In the present study not only MMP-2 but also mesangial cells were significantly increased in SHN group as compared to IgAN patients. Moreover, our correlative study on MMP-2 discovered in both IgAN as well as SHN groups significant positive correlations between glomerular immunoexpression of MMP-2 and mesangial cells. These results are in agreement with observations of others authors [21-23] that MMP-2 play a crucial role in proliferation of the mesangial cells. In addition, significant positive correlation existed in these groups between glomerular immunoexpression of MMP-2 
and glomerular $\alpha$-SMA staining. This result support previous observations [20] that MMP-2 is required for -smooth muscle actin positive mesangial cell phenotype and presumably play an important role in ECM remodeling during the development of mesangial injury. Furthermore, Sanders et al. [18] documented that in ANCA-associated glomerulonephritis MMP-2 positive mesangial cells were also $\alpha$-SMA positive.

In SHN patients significant positive correlation was noted between glomerular immunoexpression of MMP2 and glomerular monocytes/macrophages. In IgAN group this correlation was also positive, but it did not reach statistical significance. Monocytes/macrophages are important effector cells in both the adaptive and the innate immune response and their accumulation is a prominent feature in most types of human glomerulonephritis [24]. There is a wide range of factors potentially secreted by stimulated CD $68+$ cells, such as cytokines, growth factors and metalloproteinases [25]. Double labeling study clarified that CD 68 positive macrophages produced MMP-2 [18]. Our correlative study on MMP-2 and CD68+ cells seems to be in concordance with these findings, however we are aware that a morphometric analysis does not lend itself to establish such casual associations.

Finally, we found strong glomerular immunoexpression of MMP-9 but it did not differ significantly in IgAN and SHN groups. As correlations between MMP-9 and mesangial cells, $\alpha$-SMA staining and CD $68+$ cells were also weak and not significant, the role of this gelatinase in activation of mesangial cells seems to be uncertain in both IgAN and SHN groups.

In conclusion, our results confirm increased glomerular staining of MMP-2 but not MMP-9 in SHN patients. A suggestion that augmented mesangial cells proliferation in these cases depends on MMP-2, $\alpha$ SMA and monocytes/macrophages needs further investigations including double staining study.

Acknowledgements: This work was supported by MNiSW grant NN402088735

\section{References}

[1] Meadow SR, Scott DG. Berger disease: Henoch Schoenlein syndrome without the rash. J Pediatr. 1985;106:27-32.

[2] Davin JC, Ten Berge IJ, Weening JJ. What is the difference between $\operatorname{IgA}$ nephropathy and Henoch-Schoenlein purpura nephritis? Kidney Int. 2001;59:823-834.

[ 3] Berger J, Yaneva H, Nabarra B, Barbanel C. Recurrence of mesangial deposition of IgA after renal transplantation Kidney Int. 1975;7:232-241

[4] Emancipator SN. IgA nephropathy: Morphologic expression and pathogenesis. Am J Kidney Dis. 1994;23:451-462.

[ 5] Valentin MRJ. Presence of circulating macromolecular IgA in patients with hematuria due to primary $\operatorname{IgA}$ nephropathy. $\mathrm{Am}$ J Med. 1983;74:375-381.
[ 6] Sanders JT, Wyatt RJ. IgA nephropathy and Henoch-Schoenlein purpura nephritis. Curr Opin Pediatr. 2008;20:163-170.

[ 7] Marti HP. The role of matrix metalloproteinases in the activation of mesangial cells. Transpl Immunol. 2002;9:97-100.

[ 8] Catania JM, Chen G, Parrish AR. Role of matrix metalloproteinases in renal pathophysiologies. Am J Physiol Renal Physiol. 2007;292:F905-F911.

[ 9] Toth M, Chvyrkova I, Bernardo MM, Hernandez-Barrantes S, Fridman R. Pro-MMP-9 activation by MT1-MMP/MMP-2 axis and MMP-3: role of TIMP-2 and plasma membranes. Biochem Biophys Res Commun. 2003;308:386-395.

[10] Cheng S, Lovett DH. Gelatinase A (MMP-2) is necessary and sufficient for renal tubular cell epithelial-mesenchymal transformation. Am J Pathol. 2003;162:1937-1946.

[11] Cheng S, Pollock AS, Mahimkar R, Olson JL, Lovett D. Matrix metalloproteinase 2 and basement membrane integrity: a unifying mechanism for progressive renal injury. FASEB J. 2006;20:E1248-E1256.

[12] Liu Y. Renal fibrosis: New insight into the pathogenesis and therapeutics. Kidney Int. 2006;69:213-217.

[13] Weibel ER: Point Counting Methods; in Weibel ER: Stereological Methods, London: Academic Press; vol.1,1979 pp. 101-159.

[14] Urushihara M, Kagami S, Kuhara T, Tamaki T, Kuroda Y. Glomerular distribution and gelatinolytic activity of matrix metalloproteinases in human glomerulonephritis. Nephrol Dial Transplant. 2002;17:1189-96.

[15] Martin J, Eynstone L, Davies M, Steadman R. Induction of metalloproteinases by glomerular mesangial cells stimulated by proteins of the extracellular matrix. J Am Soc Nephrol. 2001;12:88-96.

[16] Eddy AA. Molecular insights into renal interstitial fibrosis. $J$ Am Soc Nephrol. 1996;7:2495-2508.

[17] Furness PN. Extracellular matrix and kidney. J Clin Pathol. 1996;49:355-59

[18] Sanders JS, van Goor H, Hanemaaijer R, Kallenberg CG, Stegeman CA. Renal expression of matrix metalloproteinases in human ANCA-associated glomerulonephritis. Nephrol Dial Transplant. 2004;19:1412-1419.

[19] Whatling C, McPheat W, Hurt-Carnejo E. Matrix management. Assigning differential roles for MMP-2 anad MM-9 in vascular remodeling. Arterioscler Thromb Vasc Biol. 2004;24:10-11.

[20] Turck J, Pollock AS, Lee LK, Marti HP, Lovett DH. Matrix metalloproteinase 2 (gelatinase A) regulates glomerular mesangial cell proliferation and differentiation. J Biol Chem. 1996;271:15074-15083.

[21] Marti HP. The role of matrix metalloproteinases in the activation of mesangial cells. Transpl Immunol. 2002;9:97-100.

[22] Turck J, Pollock AS, Lovett DH. Gelatinase A is a glomerular mesangial cell growth and differentiation factor. Kidney Int. 1997:51:1397-400.

[23] Lovett DH, Johnson RJ, Marti HP, Martin J, Davies M, Couser WG. Structural characterization of the mesangial cell type IV collagenase and enhanced expression in a model of immune complex-mediated glomerulonephritis. Am J Pathol. 1992;141:85-98.

[24] Nakopoulou L, Lazaris AC, Boletis I et al.. The expression of matrix metalloproteinase-11 protein in various types of glomerulonephritis. Nephrol Dial Transplant. 2007;22:109-117.

[25] Nikolic-Paterson DJ, Atkins RC. The role of macrophages in glomerulonephritis. Nephrol Dial Transplant. 2001;16 Suppl $5: 3-7$. 